\title{
COMMUNITY SUPPORT - THE MISSING LINK IN INDIGENOUS LANGUAGE PROMOTION IN SOUTH AFRICA?
}

$\mathrm{Ke} \mathrm{Yu}$

Human Sciences Research Council

Siphesihle Dumisa

Human Sciences Research Council

Literature on the challenges facing indigenous languages in South Africa often highlights the proverbial policy-practice gap among many other constraints. Drawing on lessons from language policy implementation programmes in other countries, this article offers a critical examination of how the policy-practice gap is potentially driven by a glaring lack of cultivating community support. Although community support has been proven to be crucial in implementing language policies around the world, in South Africa the language policy is designed and implemented from a largely top-down approach. The article provides a brief analysis of the activities of selected non-state actors who promote indigenous languages in the country. It concludes by proposing that greater attention be paid to community support as a necessary and critical step towards ensuring more positive outcomes in promoting indigenous languages in South Africa.

\section{Keywords}

Indigenous languages; African language; community support; language attitude; language policy; South Africa

\section{INTRODUCTION}

South Africa's commitment to promoting indigenous languages has been evident from the founding of democracy and was enshrined in the new constitution in 1996. Under the principle of inclusiveness, linguistic rights were recognised as fundamental human rights, and the Constitution (ch.1 section 6) specifically emphasised the need to achieve 'parity of esteem' among the 11 official languages. Taking into account historical oppression and marginalisation against the nine indigenous languages before apartheid was abolished, responsibility is put on the state to take 'practical and positive measures' towards increasing the use and status of indigenous languages. Language planning policies are mainly implemented through four government departments, namely: (i) Arts, Culture and Heritage; (ii) Communications; (iii) the two ministries of Education; as well as (iv) Justice and Constitutional Development (Beukes, 2004). Government also established the following agencies and policies, among others, to fulfil its responsibility:

- The Pan South African Language Board (PanSALB) was established in 1995. 
- The Commission for the Promotion and Protection of Cultural, Religious and Linguistic Communities was established as one of the independent chapter 9 institutions of the state in 2002.

- A Language Task Group (LangTag) was formed in 1996 by the Department of Arts, Culture, Science and Technology. Findings and recommendations from LangTag led to the appointment of a Language Policy Advisory Panel which, together with the National Language Service in the Department, developed a draft language policy.

- The language policy in education was adopted in 1997 and a similar policy for the higher education sector was developed in 2002.

- The National Language Policy Framework (NLPF) and Implementation Plan: NLPF were adopted in 2003.

- The Use of Official Languages Act 12 of 2012 was adopted and came into effect in 2013, requiring all national departments, public entities, and public enterprises to establish a Language Unit, except where exemption is sought and permitted.

However, in spite of these admirable efforts, 'nothing of real substance has changed since 1996 regarding the language political state of the ALs [African languages] ... the ALs are still not being used meaningfully in public life: in parliament, courts of law, universities, schools and the printed media' (Webb, 2013:179, see also Webb, 1999). Dirven and Polzenhagen (2004, cited in Van der Walt, 2004) are not alone in criticising the policy intention as too idealistic and romantic (see also Chew, 1999; Edwards, 1995; Turner, 2012; Webb, 1999, 2013). Hill (2010) questions the very coherence of the language policy, drawing attention to the lack of clarity on the conceptualisation of 'language status'. Ngcobo (2012: 181) further criticises that the policy 'is always in a state of change and transformation; it is a text which lacks authorship and meaning', making it open to a wide variety of interpretations.

Many scholars have also noted the politicised nature of language planning in South Africa (Cele, 2004; Foley, 2004; Webb, 1999, 2013). Cooper (1989, quoted in Van der Walt, 2004: 824) postulates that 'elites and counter-elites may be slow to alter the status quo precisely because they may share ... the evaluation which they ultimately seek to change'. Alexander (2003: 14) similarly criticises that 'the African elites ... have made no more than nominal gestures towards equipping the indigenous languages of the continent with the wherewithal for use in powerful and high-status contexts'. Poor implementation is another factor blamed for undermining efforts to promote indigenous languages and uphold the principle of 'parity of esteem'. Implementation failures are said to be largely due to insufficient consideration on the practicality of the policy intention. For instance, the difficulties in balancing the interests of all 11 official languages; slow progress in linguistic development (including standardisation and making them relevant to science, technology and advanced literature); a low turnover in training teachers who can teach in indigenous languages; and utility of the indigenous languages at higher levels of education, business and commerce remains low (Cele, 2004; Foley, 2004; Tshotsho, 2013; Webb, 2013). Another factor frequently identified is the insufficient support and demand from general indigenous language communities due to the perceived low value and esteem of the languages (Blommaert et al, 2005; Foley, 2004; Tshotsho, 2013; Turner, 2012; Webb, 1999, 2009, 2013).

This article provides a comparative analysis of South Africa's language reform experience alongside experiences from other parts of the world. It first presents selected successful and failed language planning stories in search of lessons that are relevant and instructive for South Africa. The article then reviews activities aimed at supporting indigenous languages from selected non-state actors in South Africa. The article concludes by highlighting the need 
to refocus on the rights of the indigenous language speaking communities, rather than focusing on indigenous languages themselves in implementing the language policy. It suggests that promoting indigenous languages should attend more deliberately to the specific functional areas that the indigenous language speakers embrace.

\section{SUCCESS AND FAILURE STORIES OF PROMOTING AND REVITALISING INDIGENOUS LANGUAGES}

The interest to revitalise the use of indigenous language is not unique to South Africa. The crowding-out effect of English dominance is a challenge faced by not only many indigenous languages, but even some larger European languages. Many programmes have been initiated in response to this perceived threat. Because of their greater vulnerability, most of these programmes (although not all) have come from the smaller language groups. A general observation that can be made when reviewing these programmes is that successful stories are few and far apart, while most programmes have yielded limited success, if not outright failure. This section illustrates and analyses the most well-known success stories and two selected failure stories.

The revitalisation of Modern Hebrew has been repeatedly highlighted as the best example of how a language can be revived. Hebrew transformed from being a 'dead' language (not spoken as a mother tongue) to a living language used daily by 9 million speakers (of which 7 million speak it fluently) (Klein, 2013) in less than a century. 'No other [revival] attempt has had anywhere near the success of Hebrew' (Kaufman, 2005: 6). In reviewing the revival experience, it is important to point out the many unique factors and historical events that have contributed to such unprecedented success. This includes:

- Although it was not spoken as a native language at the time of its revival, Hebrew had always existed as a religious language in written and oral prayer form. As a religious language, Hebrew was always seen as a sacred language of the ancestors and therefore enjoyed great prestige.

- The revival coincided with the period of Jewish modernisation and the nationalism movement. Strongly driven by ideology, Hebrew was seen as a tool to 'protect and unite the Jews of the Diaspora against external assimilation' (Kaufman, 2005: 3).

- Ben Yehuda - often called 'the father of Modern Hebrew' - played a critical role in driving the revival, 'but the revival effort itself was very decentralized ... He acted as a catalyst and kept things moving, but ultimately it was the individual speakers who revived the language and they did it mostly without the control or guidance of any leader' (Kaufman, 2005: 1, emphasis added).

- Jews spoke many languages at the time; none was regarded as suitable to become the commonly accepted dominant language. Hebrew emerged within this context as an accepted common language.

- Over the course of the revival, various streams of Jewish immigrants arrived from Europe 'with the intention of radically changing their way of life ... changing their language along with all the rest was not that much more' (Kaufman, 2005: 6). The immigrants mostly lived in semi-isolated farms, which allowed them 'to together make a switch to a language without needing the wider world to go along with them' (Kaufman, 2005: 3).

- Most particularly, the youth within the migrant community started popularising the language among themselves as their private language (which their parents knew less of than they did). This facilitated Hebrew's transmission to the next generation. 
Another factor that might have contributed to the success was the timing of the revival: at the beginning of the 1990s English had not yet established its prominence as the world's lingua franca.

Besides Hebrew, other successful languages revival stories include some of the indigenous languages. One example is the Hawaiian immersion programme that 'is arguably the most dramatic language revitalisation success story to date' (Little \& McCarty, 2006:14). Like other indigenous languages, Hawaiian went from being the predominant language before the arrival of Europeans and Americans, experienced a steep decline thereafter, and was reinstated as a co-official language alongside English under a bilingual system. The Hawaiian immersion programme started from family-run preschools in 1983 where children were encouraged to interact daily with other Hawaiian speakers. The Hawaiian culture, world view, spirituality, morality and social relations were closely built into the programme so that language and culture developed simultaneously. The children were required to use Hawaiian exclusively during these programmes. Parents later on also pressured the state to provide full immersion programmes until end of primary or secondary education. Children who went through the programme were found to achieve equal and sometimes better results than the children enrolled in English-only schools, 'even in English language arts' subjects (Little \& McCarty, 2006: 18).

Navajo (in America), Pueblos (in America), Hualapai (in America), Māori (in New Zealand), and Cree (in Quebec) are other indigenous languages that went through similar experiences and gained moderate achievements (Gallegos et al., 2010; Little \& McCarty, 2006; Spolsky, 1995; Stoles, 2014). Scholars have highlighted critical factors to their success as follows:

- the integral partnership of language and culture in the design of the programmes;

- the involvement of children from an early age; and

- the strong commitment and involvement/support from local community (including parental involvement) and educational institutions.

Common challenges, on the other hand, mainly include teacher availability, teaching training, and limited funding and development of written materials. In all cases, the primary focus was put on maintaining the language as an everyday language of communication among families and communities, thus prioritising the oral form more than the written form. These programmes also mainly serve as a transitional plan - with the programmes starting when the children are young and being gradually phased out as they progress to higher grades. None of these languages serve as a permanent Medium of Instruction (MoI) or subject at the advanced level of learning.

These success stories are no doubt encouraging. However, Edwards (1985) repeatedly shows in his chapter on language revival efforts that the successes are in the minority. Instead, failures in language planning are much more common. Two examples are discussed here. The first is Hong Kong. Under colonial rule, schools in Hong Kong were free to choose their MoI, and many opted for English. When the People's Republic of China resumed in 1997, Hong Kong adopted a mother-tongue language policy amid political considerations, and research evidence that shows a positive correlation between mother-tongue instruction and students' performance (Fung \& Ma, 2012). The policy posed restrictions on government and government-aided schools that could continue to use English as the MoI. Schools which wished to retain English at the MoI had to apply for exemption and the majority were therefore forced to adopt Chinese. Pupils and parents were the strongest voices rallying and 
petitioning against the policy: they viewed the language switch as a 'downgrading of their school ... English education remain[ed] the preferred economic choice' (Mok \& Li, 2010: 561, 576). 'Parents shifted their preference from public and government aided schools to private and international schools' (Mok \& Li, 2010: 561). Sometimes parents would even 'seek alternatives by either sending their children or moving the whole family to overseas for the pursuit of English education' (Mok \& Li, 2010: 576). ${ }^{1}$ An interim review was conducted in 2005, which found that performance in English and the subject called Use of English (a prerequisite for university entry in Hong Kong) of those students in Chinese MoI schools had declined significantly (Fung \& Ma, 2012). In 2009, the Hong Kong government announced a 'fine-tuned' policy which reverted back to the pre-reform arrangement.

The other example comes from Malaysia. Following its independence in 1957, a great wave of enthusiasm in nation building led to Bahasa Melayu being endorsed as Malaysia's official language. The government deliberately chose to reduce the role and status of English in its administrative and everyday use, and established programmes to modernise and develop Bahasa Melayu. 'From being the sole medium of instruction in the education system during colonial times, English was relegated to being taught in schools as second language; in fact in the rural areas where there was almost no environmental exposure to the language, English was virtually a foreign language' (Gill, 2005: 244). Bahasa Melayu was set to be used in all government functions, as well as be the MoI in the public schooling systems, including universities. However, the development of Bahasa Melayu was frustratingly slow: translation could not keep up with the explosion of knowledge generated in English; and when material could not be made available in Bahasa Melayu, students reverted to English. In addition, although the government had absorbed a large proportion of the graduates from public universities (where Bahasa Melayu was the MoI), when the civic demand saturated, many of these students found themselves unemployed because their English was inadequate for employment in the private sectors. This served to perpetuate the old perception that English offered better social opportunities and that ethnic Malays were disadvantaged in this regard because they attended Bahasa Melayu schools (as opposed to non-Malays, the Chinese and Indians, and Malays who had attended English-medium schools). As the private sector gradually became the main employment choice for graduates, private universities using English as the MoI mushroomed. In 2002, the Malaysian government reversed the policy and no longer insisted on Bahasa Melayu being the MoI in its public schooling system (Gill, 2005).

\section{COMMUNITY ENGAGEMENT AS A CRITICAL FACTOR IN LANGUAGE PLANNING}

Multiple lessons can be extracted from the above cases: they all caution about the proverbial policy-practice gap and warn against policies that are too optimistic in setting their intended outcomes; they all point to the struggle indigenous languages face against perceived low utility and lack of prestige; they all point to the importance of strong will (often propelled by ideology) in successfully promoting indigenous languages; and most importantly, they all highlight the critical importance that communities play in ensuring a positive outcome for language policies. Many authors (eg. Bamgbose, 2011; Edwards, 1985; Van der Walt, 2004; Yamamoto et al., 2008) echo Crawford's $(1995: 50,56)$ claim that:

Language shift is determined primarily by internal changes within language communities themselves ... [It may respond to external pressure, but], ultimately speakers themselves are responsible, through their attitudes and choices, for what 
happens to their native language ... language shift cannot be reversed by outsiders, however well-meaning.

The above cases also show that communities may play different roles in promoting or impeding the development of indigenous languages. One is to ensure that language, as an instrument of oral communication, continues. Fishman $(1991,1995)$ asserts that endangered languages become endangered only when intergenerational language transmission is interrupted, ultimately producing fewer and fewer speakers in each generation because parents do not transmit the language to their children. The most endangered languages are those which are only spoken by a few elders, Fishman (1991) suggests in his eight stages of language loss. Therefore, he suggests that focusing on intergenerational transmission of language should be the most fundamental step to reverse language shift. The successful revival stories of the small native languages are testimony to this.

However, the cases also show that communities can easily become inhibitors in the maintenance or advancement of indigenous languages, particularly when they are not convinced of the utility and prestige of their own languages. Literature strongly argues that whether an indigenous language is valued by the community or not is a vital component of language promotion (Hornberger, 1998). The Hong Kong case illustrated above is a good example of this. Because of the colonial history, indigenous languages in Africa have also been particularly vulnerable to their speakers' negative attitudes towards them. Reviewing the language situation in four African countries (Kenya, Tanzania, Central African Republic and Nigeria), Fasold (1997) notes that many African language speakers often oppose using their indigenous languages in schools. Resistance towards mother-tongue instruction is also common among many members of the language communities in South Africa, especially those of lower socio-economic status (Aziakpono \& Bekker, 2010). Chick and Wade (1998, cited in Minow, 2010) also note this class divide in their study where English remains the dominant lingua franca for the educated elite, while isiZulu remains dominant among the working-class Zulus. Literature has demonstrated that attitudes towards language are intricately associated with the status and power the language enjoys (Leibowitz, 2005). So it seems natural that many of the working class will be primarily interested in advancing their social capital and will perceive 'English as offering greater socio-economic and educational opportunities' (Mda, 2004: 169). In this sense, to deny them this right could be to impose further disadvantage on them. The rhetoric regarding language as a salient marker of identity contributing to a sense of belonging, self-worth, and unity may have emotional appeal, but it is 'not possible to bring about widespread language shift when the appeal is made on the basis of abstraction like culture, heritage or tradition. These are not, of course, trivial or ignorable aspects of life, but they are no conscious priority for most people' (Edwards, 1985: 64).

Awedoba's (2001) findings in Ghana are thus not atypical in Africa: home is associated with local language, local culture, tradition, illiteracy and hoe; and school is associated with English, European ways, modernity, literacy and pen (also see Shizha comments on Zimbabwe, 2012). This dichotomy could prompt people to downplay their Africanness and everything associated with it, including language, in exchange for an urban or modern identity (Mda, 2004).

Research has also demonstrated that urban societal multilingualism often includes shifts in identities according to domains (De Kadt, 2005). Bilinguals - as many of the indigenous 
language speakers are - largely choose 'a particular language(s) in a particular situation, determined by the context in which the language is used, i.e. the function, the audience and the message for which it is employed' (Department of Arts and Culture, 2003: 19). This is consistent with research on actual language practice in various contexts (eg. Nongogo, 2007). These choice are often fluid, at times ambivalent, and 'alternate back and forward all the time' (Kapp \& Bangeni, 2011: 204). Kapp and Bangeni (2011) have also recorded incidents where English is 'Afranised' to signal a specific township identity. Recent studies in South Africa have also recorded instances of learners expressing appreciation of their indigenous languages (e.g., Dyers, 2007; McKinney, 2007; Rudwick, 2008). Sometimes, learners may even risk derision and humiliation from their peers if they publicly assert their preference for English rather than their own language (Kapp, 2004; Kapp \& Bangeni, 2011).

The role of schools needs to be highlighted in this discussion. Schools are fundamental in restoring minority and endangered languages (Edwards, 1985). However, schools are often regarded as an outside institution in certain communities, 'unless they are under effective local control' (Crawford, 1995: 56). Crawford (1995: 56) further maintains that 'even when there is effective local control, schools can only do so much'. Fishman (1995: 171) explains why:

Schools are normally programmed and not inter-generational, and mother-tongues are intergenerational and not programmed ... vernacularization is the opposite of institutionalization ... [therefore] acquiring the beloved language in school must have ample out-of school and after-school informal interlocutors, places, and topics to see him or her through to his or her own child-bearing stage.

In addition to the logic behind Fishman's argument, language practices in higher education and employment also greatly influence the language choices in lower educational level, as both the example from Hong Kong and Malaysia attest. As community support is found to be correlated with the economic value that they believe the language carries, whether or not a language is used for higher education and in the work place is a critical consideration when the language speakers choose which language they want their children to be taught in.

These lessons point to the limitations of a top-down approach in achieving multilingualism and the importance of complementing it with a bottom-up approach in order to promote indigenous languages more successfully (see Hornberger, 1998). Similar to the Malaysian case, however, the language policy in South Africa has largely been top-down. The next section seeks to uncover the extent to which the promotion of indigenous languages in South Africa has taken a bottom-up approach.

Before we report on activities around indigenous languages, we need to first highlight that data pertaining to attitudes towards indigenous languages in South Africa is scarce. While StatsSA collects regular data on language practices (i.e., first language and second language spoken); it does not collect data on attitudes towards languages. The South African Social Attitudes Survey does ask people's opinion on which language should be used as the language of instruction in secondary and higher education, in addition to which language people speak at home, but language preferences outside of the educational domain are largely omitted. The other main source of nationwide information on language attitudes is the PanSALB survey results of 1999 , which showed that $12 \%$ of the population supported the use of English as the main language of teaching in education while the majority of South 
Africans (88\%), mostly non-English first language speakers, were in favour of a bilingual or multilingual education system. This source is, however, outdated.

In the absence of large-scale national quantitative data, a qualitative approach relying on selected case studies is adopted in the next section. The focus is on the activities around the support of indigenous languages from non-state actors. The essential caveat of this approach is that it is not an exhaustive representation of all community activities around indigenous languages. The aim, however, is to show the level of awareness and commitment to promoting indigenous languages among a number of champion organisations operating within the academic and civil society realm.

\section{NON-STATE ACTORS PROMOTING INDIGENOUS LANGUAGES IN SOUTH AFRICA}

This section has three objectives: firstly, to identify some of the main groups and associations promoting indigenous languages in South Africa and their reasons for doing this; secondly, to briefly discuss the activities they engage in and offer an appraisal of the achievements and limitations of these activities thus far; and lastly, to determine the potential opportunities and limitations that may arise in further pursuing a bottom-up approach.

Two types of groups exist in the South African language promoting landscape: those which focus on promoting language primarily as a function of education, and those which incorporate language promotion within a larger framework of cultural preservation, where language is regarded as one aspect of cultural identity. The actors can also be classified into academic actors and civil society organisations.

The main academic entities include:

- the Linguistics Society of Southern Africa (LSSA), established in the 1960s, which produces the Southern African Linguistics and Applied Language Studies Journal together with SAALA;

- the Southern African Applied Linguistics Association (SAALA), founded in $1980 ;{ }^{2}$

- the South African Association for Language Teaching (SAALT), founded in 1966, which independently produces the Journal for Language Teaching; and

- the African Language Association of Southern Africa (ALASA), established in 1979, which is affiliated with the South African Journal of African Languages.

Over several decades these associations have played a critical role in shaping the discourse around indigenous languages. ${ }^{3}$ Their activities mostly include hosting annual academic conferences and regular seminars, in addition to their knowledge contribution through journal articles. All these associations represent a community of scholars, researchers and teachers who explicitly express commitment to promoting multi-lingual language planning, policy and practice in South Africa.

The Centre for Advanced Studies on African Societies (CASAS) was founded as a non-profit organisation in 1997. ${ }^{4}$ It operates in the academic arena dealing with a broader mandate of Pan-Africanism and research on African societies. Indigenous languages are incorporated into the focus of CASAS as one aspect of preserving and resuscitating African cultures. The centre organises workshops, conferences, seminars and colloquia, and produces various types of publications. In 2007, CASAS released a report on the challenges of promoting indigenous 
languages in South Africa based on research commissioned by the Foundation for Human Rights in South Africa. The report, authored by Prah (2007), underscores how education, human development and modernity relate to language and culture, and argues that the socioeconomic and cultural disadvantages faced by many indigenous language speakers contributes to a vicious cycle where they themselves do not possess enough will and capacity to promote their own languages.

There is also an active network of education NGOs which advocate against English dominance. An essential part of the advocacy done by these NGOs is to make books available to children in their mother tongue through donations to local community libraries, and availing free learning and reading material in newspapers and online platforms. Some also provide ongoing support to community reading clubs. They essentially argue that children must be given the opportunity to read, write and learn in their home languages from an early age. These education NGOs see the functional value of indigenous languages as an essential part of self-identity during early childhood development. Through community events, they aim to create awareness about the importance of indigenous languages among members of the general public. Free supplements of stories and learning materials in indigenous languages in newspapers help raise awareness about the importance of indigenous languages among other newspaper readers. For example, the aim of Nal'ibali, a children's literature $\mathrm{NGO}^{5}$ is to publish, promote and develop children's books in all 11 official languages. On 21 February 2014, International Mother Language Day, Nal'ibali organised an online 'tweets' campaign, canvassing celebrities to write their tweets for the day in their indigenous language in order to create awareness around the importance of the day. Similar NGOs include the South African Translators Institute, Biblionef, Little Hands and Puo. Biblionef has commissioned the translation of over 83 book titles into one or more of South Africa's 11 official languages since it was founded in $1998 .{ }^{6}$ Puo supplies the African language content for the Apple iPad Schools Project, which is described as a 'South African curriculum version of iStore'. As the successful indigenous language revival cases in the earlier section show, involvement of children from an early age does yield positive results. Early childhood development is an important platform which has been used to restore marginalised languages in other countries. These literacy campaigns are also an interesting avenue to address stagnation in indigenous language written formats, where indigenous languages are often underdeveloped.

The Molteno Institute of Mother Tongue Language and Literacy focuses on assisting with retraining foundation and primary school educators to improve their ability to teach in indigenous languages. Together with the Department of Education, Molteno equips teachers with materials and skills to facilitate teaching in indigenous languages, especially in the first six years of schooling. ${ }^{8}$ In a media statement following an interview on SABC Talk in May 2013, Molteno's CEO, Masennya Dikotla, argued that learning in indigenous languages in rural schools could enable youth to think innovatively in their home language, so their skills and education would be relevant to their rural communities and they wouldn't be tempted to migrate too easily.

The link between language, culture, and human/community development lies at the centre of the work done by the Kara Heritage Institute and Ebukhosini Solutions. ${ }^{9}$ These two organisations seek to achieve community development by highlighting the pivotal role of cultural heritage and traditions and thus empower communities to preserve and take pride in their African cultures. Through private-public partnerships, these organisations manage various projects which encourage local community development through social 
entrepreneurship, arts and crafts programmes, agricultural cooperatives, and leadership academies. However, neither of the two explicitly focuses on indigenous language development; instead, they view language as part of culture. This focus is similar to the indigenous language revival cases reviewed earlier and offers a more integrated platform to resonate with indigenous speakers' needs.

There are also civil society organisations which intervened in the indigenous languages debate from a human rights perspective. In 2011, 34 civil society organisations, led by Cerneels Lourens, 'motivated by a belief in the benefits of multilingualism in all spheres of life, rather than by narrow ethno-nationalist considerations ... with a view to crafting a framework that will take [South Africa] beyond mere rhetoric and beyond the desire of most middle-class people' (Alexander, 2012), opened and won a court case on the SA Draft Languages Bill to force the state to pass the bill which had been shelved since 2003 as a matter of urgency.

A few observations can be made regarding the activities implemented by the non-state actors thus far. Firstly, the academic associations do not focus on having direct contact with communities, as their work is aimed at shaping discourse around indigenous languages and contributing towards making policy recommendations. Secondly, by and large, advocacy tends to happen at the level of formal organised civil society led by experts in the field, who are often not mother-tongue indigenous language speakers themselves. None of the organisations discussed here was formed organically by indigenous language speakers at a grassroots level of community organising. This could be due to the different primary concerns of the language speakers. It might also reflect insufficient interaction between organisations and indigenous language communities. Thirdly, the civil society organisations engaged in the language debate from a human rights perspective also essentially aim to make policy interventions and contributions rather than directly mobilising or empowering communities. Lastly, the NGOs have not tapped into elite voices, particularly those from political elites, as a resource to drive their agenda. The only activities directly involving communities are the early childhood development literacy projects.

\section{DISCUSSION}

There seems to be a dilemma regarding language planning. It 'ultimately should be a function of the needs of the population' (Edwards, 1985: 90), but 'by the time languages are seen to be in need of sustenance, their position is often irretrievable' (Edwards, 1985: 86). The answer to resolve this dilemma lies at the heart of how to choose the appropriate focus in implementing South Africa's language planning policy.

The case studies reported in this article, as well as the literature we have surveyed, have supported the necessity of a bottom-up approach in promoting indigenous languages and the critical role attitudes towards the languages play in rallying the necessary community support. In this sense, we believe a critical first step towards a more successfully indigenous language promotion in South Africa is to endorse Prinsloo's (2011) proposal that it should be the rights of the language speakers, rather than the rights of the language, that captures the essence of the debate on indigenous languages in South Africa. In practice, this means that the rights and needs of the speakers have to be incorporated as a focal point in the design of the South African language planning policies first and foremost. Secondly, South African language planning policies should identity and strengthen the functional areas the indigenous language speakers have themselves embraced. Research evidence suggests that indigenous 
language speakers tend to embrace the indigenous language in the oral and cultural domains, and in relation to identity. Therefore, language planning in South Africa must recognise the limitations of school and formal institutions in promoting indigenous languages, and pay more attention to the public and oral domains (Bosch \& De Klerk, 1996), including public speeches, popular media, and communication that entails personal interactions (e.g., in shops and municipalities), especially in the short term. English as MoI in schools should be allowed as this language skill is directly relevant to economic advancement for the indigenous language speakers. Strategies, particularly the potential role political elites can play, should be mobilised and pursued more deliberately (Alexander, 2003).

Lastly, we want to emphasise the need for more regular and large-scale surveys on language attitudes. We echo the recommendation by the LangTag report in 1996 that calls for the establishment of 'appropriate and accurate demographic statistics, language maps, language surveys, etc. for South Africa [which] should be updated at regular intervals' as one of its long-term recommendations (LangTag, 1996). Regular and large-scale surveys will help us not only to understand and track language attitudes, but also to understand how the language speakers view their languages and trends in language fluidity.

The case study analysis shows that community support and involvement are insufficient in South Africa. Academic and civil society organisations are advocating, but so far, they have not strategically targeted cultivating community voices to support their efforts. In this sense, we agree with Grin and Vaillancourt (1999: 99), who assert that 'influencing attitudes in order for this preference [to carry out activities in the language] to emerge should be the top priority of the revitalisation policy'. We also agree with Alexander's (2003: 28) repeated appeal that 'we have to persuade our communities about the potential of African languages as languages of power and language of high status'.

\section{ENDNOTES}

\footnotetext{
${ }^{1}$ The teachers were more silent 'mostly because their attention was diverted to the new benchmark test' (Mok \& $\mathrm{Li}, 2010: 561)$, but there were other groups objecting as well on the grounds that insufficient Chinese teachers were available.

${ }^{2}$ http://linguistics.org.za/

3 www.alasa.org.za

${ }_{5}^{4}$ http://www.casas.co.za/History.aspx

5 www.nalibali.org.za

6 www.biblionef.org.za

${ }^{7}$ http://www.puo.co.za/Corporate-Social-Investment-projects.html

8 http://www.molteno.co.za/

${ }^{9}$ Ebukhosini Solutions is a registered private company which provides a number of free services related to communities in around Johannesburg. http://www.ebukhosinisolutions.co.za/services.html
}

\section{REFERENCES}

ALEXANDER, N. 2003. The African renaissance and the use of African languages in tertiary education. PRAESA Occasional Paper No. 13. Cape Town: PRAESA.

ALEXANDER, N. 2012. Language denied means citizens ignored. Mail and Guardian, 3 February 32012.

AWEDOBA, A. 2001. Examining the cases: attitudes towards an instruction in the local language. Improving educational quality project. Washington DC: American Institutes for Research. 
AZIAKPONO, P \& BEKKER, I. 2010. The attitudes of isiXhosa-speaking students toward language of learning and teaching issues at Rhodes University, South Africa: general trends. Southern African Linguistics and Applied Language Studies, 28(1):39-60.

BAMGBOSE, A. 2011. African languages today: the challenge of a prospect for empowerment under globalization. Paper presented at 40th Annual conference on African linguistics.

BEUKES, A. 2004. The first ten of democracy: language planning in South Africa. Paper presented at the Xth Linguapax Congress on Linguistic Diversity, Sustainability and Peace, Barcelona, 20-23 May.

BLOMMAERT, J, N MUYLLAERT, M HUYSMANS \& C DYERS. 2005. Peripheral normativity: literacy and the production of locality in South African township school. Linguistics and Education, 16(4):378-403.

BOSCH, B \& V DE KLERK. 1996. Language attitudes and their implications for the teaching of English in the Eastern Cape. In De Klerk, V (Ed), Focus on South Africa. Amsterdam: John Benjamins. 231-250.

CELE, N. 2004. 'Equity of access' and 'equity of outcomes' challenged by language policy, politics and practice in South Africa higher education: the myth of language equality in education. South African Journal of Higher Education, 18(1):38-56.

CHEW, P. 1999. Linguistic imperialism, globalism and the English language. The AILA Review, 13:37-47.

CRAWFORD, J. 1995 Seven Hypotheses on Language Loss Causes and Cures. Paper presented at the second Symposium on Stabilizing Indigenous Languages, Northern Arizona University, May 4, $1995 . \quad$ Available from http://jan.ucc.nau.edu/ jar/SIL/Crawford.pdf [Accessed: 22 May 2015]

DE KADT, E. 2005. English, language shift and identities: a comparison between 'Zuludominant' and 'multicultural' students on a South African university campus. Southern African Linguistics and Applied Language Studies, 23(1):19-37.

Department of Arts and Culture. 2003. National language policy framework. Available from https://www.dac.gov.za/sites/default/files/LPD_Language\%20Policy\%20Framework_E nglish_0.pdf [Accessed: 22 May 2015]

DYERS, C. 2007. Truncated multilingualism or language shift? An examination of language use in intimate domains in a new non-racial working class township in South Africa. Journal of Multilingual and Multicultural Development, 29(2):110-126.

EDWARDS, J. 1985. Language, society and identity. Oxford: Basil Blackwell.

FASOLD, RW. 1997. Motivations and attitudes influencing vernacular literacy: four African assessments. In Tabouret-Keller, ARB, P Le Page, C Gardener \& V Gabrielle (Eds), Vernacular literacy: a re-evaluation. Oxford: Clarendon Press. 246-270.

FISHMAN, JA. 1991. Revising language shift: theoretical and empirical foundations of assistance to threatened languages. Clevedon, UK: Multilingual Matters.

FISHMAN, JA. 1995. Maintaining languages: what works? What doesn't. Stabilizing indigenous languages. Paper presented at the Second Stabilizing indigenous languages symposium. May 4.

FOLEY, A. 2004. Language policy for higher education in South Africa: implications and complications. South African Journal of Higher Education, 18(1):57-71.

FUNG, D \& M MA. 2012. The changes of language policies in Hong Kong education in the post-colonial era. Paper presented at the international conference on education, applied science and management, Dubai, UAE, 26-27 December. 
GALLEGOS, C, WE MURRAY \& M EVANS. 2010. Research note: comparing indigenous language revitalisation: Te reo Māori in Aotearoa New Zealand and Mapudungun in Chile. Asia Pacific Viewpoint, 51(1):91-104.

GILL, SK. 2005. Language policy in Malaysia: reversing direction. Language Policy, 4:241260.

GRIN, F \& F VAILLANCOURT. 1999. The cost-effectiveness evaluation of minority language policies: case studies on Wales, Ireland and the Basque country. Available from http://edoc.vifapol.de/opus/volltexte/2008/796/pdf/monograph_2.pdf_Accessed: 22 May 2015]

HILL, L. 2010. Language and status: on the limits of language planning. Linguistics, 39:41 58.

HORNBERGER, NH. 1998. Language policy, language education, language rights: indigenous, immigrant, and international perspectives. Language in Society, 27(4):439458.

KAPP, R \& B BANGENI. 2011. A longitudinal study of student's negotiation of language, literacy and identity. Southern African Linguistics and Applied Language Studies, 29(2):197-208.

KAPP, R. 2004. 'Reading on the line': an analysis of literacy practices in ESL classes in a South African township school. Language and Education, 8(3):246-263.

KAUFMAN, J. 2005. The revival of the Hebrew Language. Available from http://www.jefftk.com/files/revival.pdf [Accessed: 22 May 2015]

KLEIN, Z. 2013. A million and a half Israelis struggle with Hebrew. Israel Hayom (newspaper), 18 March 2013.

LANGUAGE PLAN TASK GROUP. 1996. Summary of the Final Report presented to the Minister of Arts, Culture, Science and Technology, on 08 August 1996.

LEIBOWITZ, B. 2005. Learning in an additional language in a multilingual society: a South African case study on university-level writing. TESOL Quarterly, 39(4):661-681.

LITTLE, MER \& TL MCCARTY. 2006. Language planning challenges and prospects in native American communities and schools. Available from http://nepc.colorado.edu/files/Report-EPSL-0602-105-LPRU.pdf [Accessed: 22 May 2015]

MCKINNEY, C. 2007. 'If I speak English, does it make me less black anyway?' 'Race' and English in South African desegregated schools. English Academy Review, 24(2):6-24.

MDA, T. 2004. Education and multilingualism. In Nkomo, M, C McKinney \& L Chisholm, (Eds), Reflections on school integration. Cape Town: HSRC publishers. 163-182.

MINOW, V. 2010. Variation in the grammar of Black South African English. Frankfurt: Peter Lang.

MOK, D. \& LH LI. 2010. The spatial impact of language policies on the marginal bids for English education in Hong Kong. Growth and Change, 41(4):556-587.

NGCOBO , MN. 2012. The constitutional dynamism of a multilingual language policy: A case of South Africa. South African Journal of African Languages, 32(2):181-187.

NONGOGO, K. 2007. Mina 'NgumZulu Phaqa': language and identity among multilingual Grade 9 learners at a private desegregated high school in South Africa. English Academy Review, 24(2):42-54.

PRAH, K. 2007. Challenges to the promotion of indigenous languages in South Africa. The Centre for Advance Studies of African Society.

PRINSLOO, M. 2011. The odd couple: diverging paths in language policy and educational practices. Perspectives in Education, 29(4):1-9. 
RUDWICK, S. 2008. 'Coconuts' and 'Oreos': English-speaking Zulu people in a South African township. World Englishes, 27(1):101-116.

SHIZHA, E. 2012. Reclaiming and revisioning indigenous voices: the case of the language of instruction in science education in Zimbabwean primary schools. Literacy Information and Computer Education Journal, 1(1):785-793.

SPOLSKY, B. 1995. Conditions for language revitalisation: a comparison of the cases of Hebrew and Maori. Current Issues in Language and Society, 2:177-201.

STOLES, DB. 2014. Four successful indigenous language programs. Available from http://jan.ucc.nau.edu/ jar/TIL_21.html [Accessed: 22 May 2015]

TSHOTSHO, BP. 2013. Mother tongue debate and language policy in South Africa. International Journal of Humanities and Social Science, 3(3):39-44

TURNER, NS. 2012. African languages as compulsory courses in KwaZulu-Natal: illusory initiative for inspired intervention? Per Linguam, 28(2):28-45.

VAN DER WALT, C. 2004. The challenge of multilingualism: in response to the language policy for higher education. South African Journal of Higher Education, 18(1):140-152.

WEBB, V. 1999. Multilingualism in democratic South Africa: the over-estimation of language policy. International Journal of Educational Development, 19:351-366.

WEBB, V. 2009. Multilingualism in South Africa: The challenge to below. Language Matters, 40(2):190-204.

WEBB, V. 2013. African languages in post-1994 education in South Africa: our own Titanic? Southern African Linguistic and Applied Language Studies, 31(2):173-184.

YAMAMOTO, A, M BRENZINGER \& ME VILLALON. 2008. A place for all languages: on language vitality and revitalization. Museum International, 60(3):60-70.

\section{BIOGRAPHICAL NOTE}

$\mathrm{Dr} \mathrm{Yu}$ is a research specialist at the Human Sciences Research Council. She holds a Bachelor of Economics degree from University of Shanghai for Science and Technology in China (1998), a Master in International Business degree from the Norwegian School of Economics and Business Administration (2003), and a PhD in Educational Management and Policy Studies from University of Pretoria in South Africa (2008). Her doctoral thesis was on researcher-participant engagement in qualitative educational research. Her current research interests primarily include research governance (research impact and ethics), disciplinary characteristics and inter/trans-disciplinary evolution, identity and otherness, violence and crime, China and Africa, and comparative studies on oriental, occidental and African culture and society. Email: kyu@hsrc.ac.za

Ms Dumisa is a Master intern at the Human Sciences Research Council. 